\title{
Magnetic thermoablation stimuli alter BCL2 and FGF-RI but not HSP70 expression profiles in BT474 breast tumors
}

This article was published in the following Dove Press journal:

International Journal of Nanomedicine

10 March 2015

Number of times this article has been viewed

\section{Marcus Stapf \\ Nadine Pömpner \\ Melanie Kettering \\ Ingrid Hilger}

Institute of Diagnostic

and Interventional Radiology, Jena

University Hospital, Jena, Germany
Correspondence: Ingrid Hilger Institute of Diagnostic and Interventional Radiology, Jena University Hospital, Forschungszentrum Lobeda, Erlanger Allee I0I, D-07747 Jena,

Germany

Tel $+49364 \mid 932592$ |

Fax +49 364I 9325922

Email ingrid.hilger@med.uni-jena.de
Abstract: Magnetically induced heating of magnetic nanoparticles (MNP) in an alternating magnetic field (AMF) is a promising minimal invasive tool for localized tumor treatment that eradicates tumor cells by applying thermal stress. While temperatures between $42^{\circ} \mathrm{C}$ and $45^{\circ} \mathrm{C}$ induce apoptosis and sensitize the cells for chemo- and radiation therapies when applied for at least 30 minutes, temperatures above $50^{\circ} \mathrm{C}$, so-called thermoablative temperatures, rapidly induce irreversible cell damage resulting in necrosis. Since only little is known concerning the protein expression of anti-apoptotic B-cell lymphoma 2 (BCL2), fibroblast growth factor receptor 1 (FGF-R1), and heat shock protein (HSP70) after short-time magnetic thermoablative tumor treatment, these relevant tumor proteins were investigated by immunohistochemistry (IHC) in a human BT474 breast cancer mouse xenograft model. In the investigated sample groups, the application of thermoablative temperatures ( $<2$ minutes) led to a downregulation of BCL2 and FGF-R1 on the protein level while the level of HSP70 remained unchanged. Coincidently, the tumor tissue was damaged by heat, resulting in large apoptotic and necrotic areas in regions with high MNP concentration. Taken together, thermoablative heating induced via magnetic methods can reduce the expression of tumor-related proteins and locally inactivate tumor tissue, leading to a prospectively reduced tumorigenicity of cancerous tissues. The presented data allow a deeper insight into the molecular mechanisms in relation to magnetic thermoablative tumor treatments with the aim of further improvements.

Keywords: magnetic nanoparticles (MNP), thermoablation, in vivo, mouse model, breast cancer tumor

\section{Introduction}

The treatment of cancer via heating is considered to be a promising tool for eradicating cancer cells and/or sensitizing tumor cells for chemo- or radiation therapy. In this context, a moderate hyperthermia treatment between $42^{\circ} \mathrm{C}$ and $45^{\circ} \mathrm{C}$ for a duration of 30-60 minutes (hyperthermia) was shown to affect cellular metabolism depending upon the applied thermal doses. Ablative temperatures above $50^{\circ} \mathrm{C}$ for a treatment duration of 4-6 minutes induce irreversible damages in tumor cells and cause necrosis (thermoablation). ${ }^{1,2}$ Whereas different heating sources (eg, water bath, infrared light, etc) for heat generation have been suggested, the administration of magnetic nanoparticles (MNP) in the tumor area will induce local heating when an alternating magnetic field (AMF) is applied. ${ }^{3,4}$ Therefore, MNP act as internal heating sources and allow a highly selective inactivation of tumors with very low side effects. ${ }^{5}$

On the pathobiological level, hyperthermia treatments are known to be associated with immune modulatory effects. ${ }^{6}$ Furthermore, hyperthermia has been shown to hinder the function of cell surface receptors and transmembrane transport proteins and affect 
the fluidity and stability of cellular membranes. Moreover, the expression of multidrug resistance proteins of tumor cells was shown to be impaired after MNP exposure in connection with magnetic heating. ${ }^{7}$ Temperatures between $42^{\circ} \mathrm{C}$ and $45^{\circ} \mathrm{C}$ decrease the de novo synthesis and the polymerization of RNA and DNA molecules during protein synthesis. ${ }^{8}$ Whereas DNA damage after moderate hyperthermia treatment is reversible, at ablative temperatures DNA will be irreversibly damaged. ${ }^{9}$

One prominent protein family associated with thermal stress is the so-called heat shock protein (HSP) family. ${ }^{10}$ HSPs act as protein chaperons and modulators of protein folding. They also initiate the formation of protein complexes and act as modulators of protein degradation. ${ }^{11}$ Hence, HSPs prevent irreversible interactions between neighbor proteins that would result in functional loss. ${ }^{8}$ HSP70 is known to be upregulated in vitro immediately after heat stress at $42^{\circ} \mathrm{C}$ for 2 hours and 2 hours after heating at $43^{\circ} \mathrm{C}$ for 20 minutes, respectively. Expression levels of this protein were found to be increased up to 12 hours after hyperthermia treatment. ${ }^{12,13}$ On the other hand, HSP synthesis is inhibited at temperatures above $45^{\circ} \mathrm{C}$ depending upon the applied thermal dose and varies between different cell types. ${ }^{8}$

The fibroblast growth factor receptor (FGF-R) is widely known to play an important role in promoting tumor growth and differentiation, as well as cell survival and angiogenesis in many organs and tissues. ${ }^{14}$ Another important protein involved in cancer cell metabolism is B-cell lymphoma 2 (BCL2). It regulates cell proliferation, migration, and differentiation and protects cancer cells of apoptosis. The protein is a key mediator in apoptosis pathways upon hyperthermia treatment.

BCL2 was found to be unchanged immediately after heat shock $\left(42^{\circ} \mathrm{C}\right.$ for 1 hour), whereas it was slightly downregulated in vitro $\left(42.5^{\circ} \mathrm{C}\right.$ for 3 hours $)$ and in vivo $\left(43^{\circ} \mathrm{C}\right.$ for 1 hour), indicating its dependency on the thermal dose and heating regime (incubator vs water bath). ${ }^{15-18}$ In general, the expression of BCL2, FGF-R1, and HSP70 has been mainly elucidated in connection with hyperthermic temperatures up to $43^{\circ} \mathrm{C}$ only.

To the best of our knowledge, only little is known concerning the expression of these proteins after the administration of a thermoablative stimulus (eg, temperatures over $50^{\circ} \mathrm{C}$ ) via magnetic heating. Here, we used a mouse model of human breast cancer xenografts to provide a better understanding of the molecular mechanisms in tumor cells after exposure to a heat stimulus. In general, we were interested in the protein tumor expression profiles of BCL2, HSP70, and FGF-R1 after using magnetic thermoablative heating. Therefore, fiber-optic thermocouples were used to monitor the temperature distribution within the tumor. We expect that our data could help to further improve the treatment of tumors via (magnetic) heating.

\section{Materials and methods \\ Tumor implantation}

For tumor implantation, $200 \mu \mathrm{L}$ Matrigel (BD Matrigel ${ }^{\mathrm{TM}}$ Basement Membrane Matrix; Becton Dickinson $\mathrm{GmbH}$, Germany) containing $1 \times 10^{7}$ BT474 cells (human mammaryadenocarcinoma, Cell Lines Service, Germany) were injected subcutaneously between the shoulder blades of 6-15 week old female severe combined immune deficiency (SCID)Balb/c mice (Harlan Laboratories, the Netherlands). After implantation, tumor growth was controlled twice a week until the onset of experiments to ensure animal health. Tumor volumes ranged from $39 \mathrm{~mm}^{3}$ to $970 \mathrm{~mm}^{3}$ and were calculated by the following equation: $V=\pi / 6(l w h)$ where $l$ is the length, $w$ the width, and $h$ the height of the tumor. For anesthesia of animals, isoflurane (2\%; Actavis Deutschland GmbH \& Co. KG, Germany) was used throughout all experiments. All experiments were performed in accordance with the international guidelines on the ethical use of animals and were approved by the regional animal care committee (02-068/11).

\section{Animal treatment groups}

To investigate the effects of magnetic thermoablation on protein expression, mice were divided into two experimental groups. Group 1 (+MNP +AMF) consisted of five to six animals that received MNP, which were heated by an AMF. Group 2 (-MNP -AMF), containing three to six animals, was used as a negative control to assess protein expression without any treatment.

\section{Magnetic thermoablation of tumors}

In group 1,20-40 mg starch coated fluidMAG-D $(200 \mathrm{mg} / \mathrm{mL}$, chemicell GmbH, Germany) super paramagnetic iron oxide nanoparticles (SPION) with a hydrodynamic diameter of $200 \mathrm{~nm}$ and a clustered $70 \mathrm{~nm}$ magnetite core (multiple 10-12 nm core particles clustered to the final size of approximately $70 \mathrm{~nm}$; Figure S1) were injected intratumorally.

Afterwards, the animals were exposed to an AMF (frequency: $400 \mathrm{kHz}$; amplitude of the magnetic field strength $(H)=24.6 \mathrm{kA} / \mathrm{m}$ ) for $35-140$ seconds until reaching thermal ablative temperatures of above $60^{\circ} \mathrm{C}$ (Figure $1 \mathrm{~A}$ and $\mathrm{B}$ ). 
A

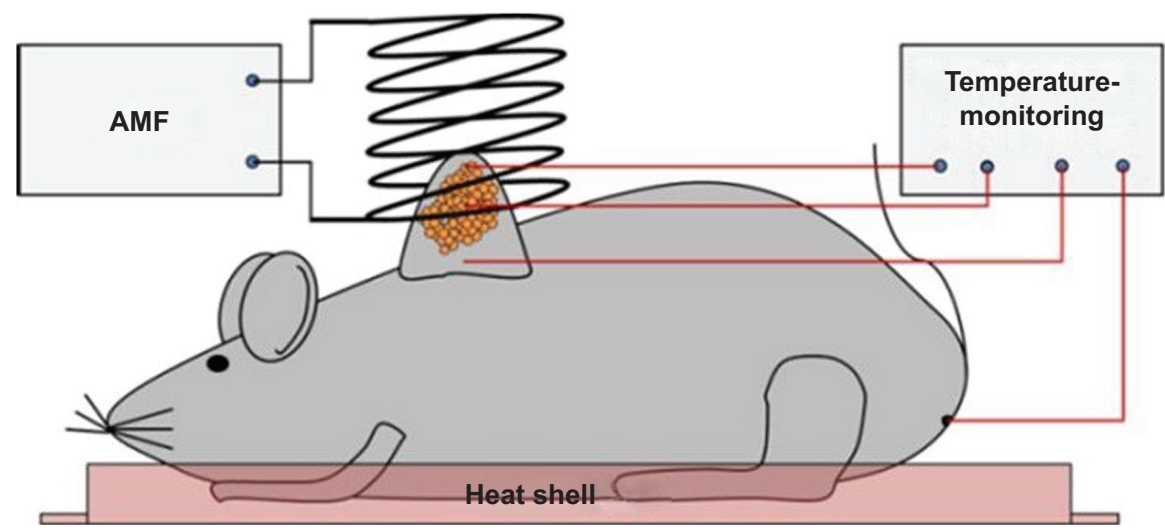

B

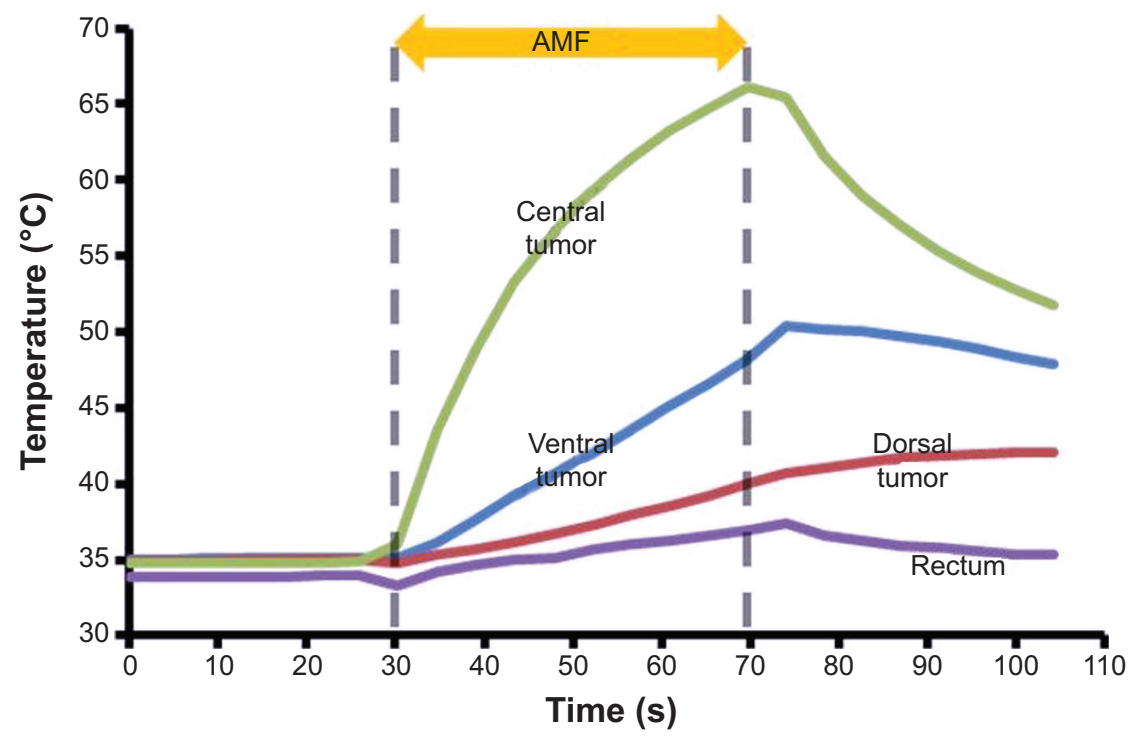

C

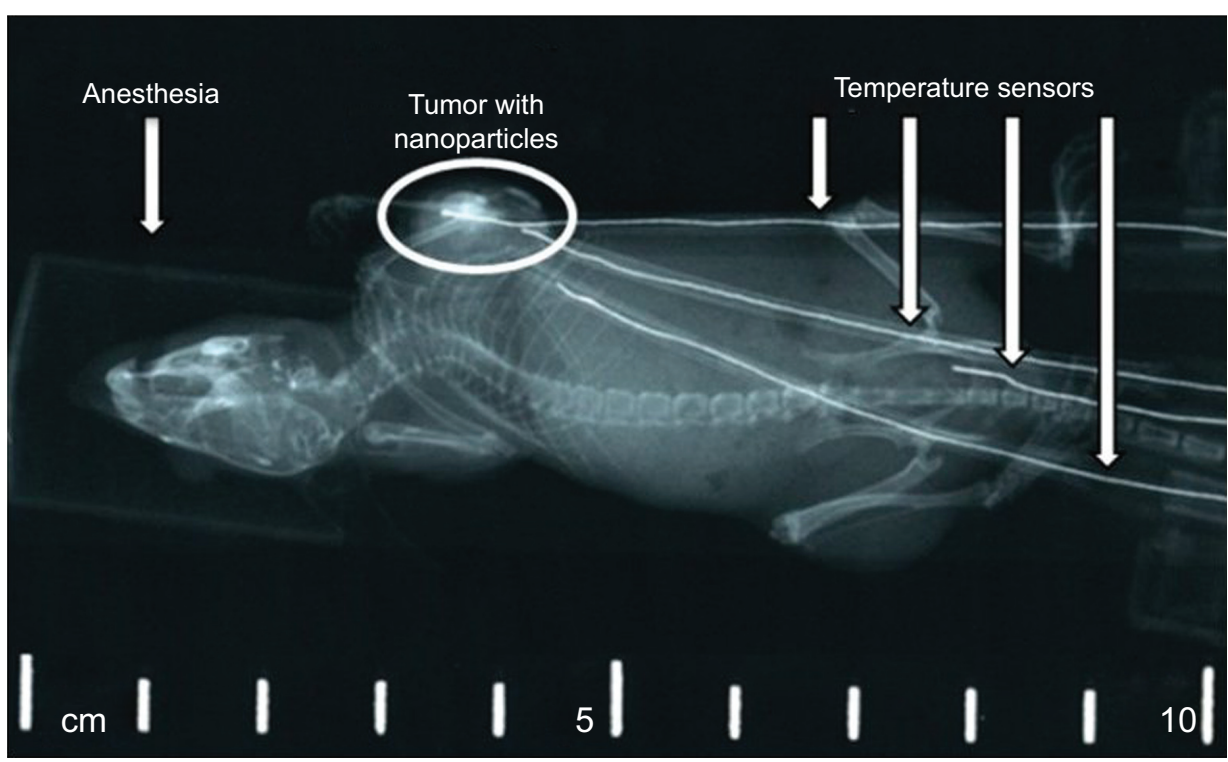

Figure I (A) Experimental set-up, (B) temperature curves, and (C) X-ray image during magnetic thermoablation.

Notes: (A) Scheme of the used experimental set-up. Nanoparticles are indicated by orange spots. (B) Representative temperature curves of different tumor regions during treatment. Body temperature was observed by thermal measurement via the rectum. Higher temperatures in the central tumor region correlate with the distribution of the administered magnetic material. After reaching ablative temperatures of approximately $65^{\circ} \mathrm{C}$, the AMF was shut-off. (C) X-ray images of mice were used to control MNP relocalization and the localization of thermocouples for thermal treatment.

Abbreviations: AMF, alternating magnetic field; MNP, magnetic nanoparticles. 
The control group (group 2) was left untreated (no MNP, no AMF). To control tumor temperatures during treatment, three fiber-optic thermocouples were inserted ventrally, dorsally, and centrally into the tumor. Additionally, one thermocouple was inserted rectally to control body temperature. X-ray images (40 kV, 2 mAs, EcoRay Orange 9020HF, Eco Ray Co. Ltd., Korea) were taken immediately after MNP injection as well as after AMF exposure (exemplarily shown in Figure 1C) to elucidate intratumoral MNP distribution as well as their potential relocalization during thermal treatment. After AMF treatment, the animals were left under isoflurane anesthesia for 2 hours. While treatment, animals were placed on a heat shell to retain body temperature and prevent hypothermia. Anesthetized animals were sacrificed afterward using $\mathrm{CO}_{2}$ and tumors were extracted for histological analyses.

\section{IHC of tumor slides}

For histological analyses, tumors were formalin-fixed and embedded in paraffin. After cutting the specimen into $5 \mu \mathrm{m}$ thick sections using a rotary microtome (HM 340 E, MICROM International $\mathrm{GmbH}$, Germany), the slides were deparaffined in xylol and decreasing ethanol concentrations (rehydration). Antigen retrieval was performed for 20 minutes with a Tris/ EDTA buffer at $98^{\circ} \mathrm{C}$. For washing the slides, Tris-Buffered Saline containing $0.1 \%$ Tween 20 was used. Unspecific binding was prevented by using Biotin Blocking System (X0590, Dako, Germany). The slides were placed in a staining chamber to prevent dehydration and stained for 24 hours at $4^{\circ} \mathrm{C}$ with $100 \mu \mathrm{L}$ of the appropriate primary antibody solution for BCL2 (anti-human, M0887, $151 \mathrm{mg} / \mathrm{mL}, 1: 500 ;$ Dako), HSP70 (anti-human, MU289-5M, 10-15 mg/mL, 1:50; BioGenex, USA), or FGF-R1 (anti-human, F4305-08, $0.5 \mathrm{mg} / \mathrm{mL}$, 1:5; Biomol, Germany), respectively. For detection, a goat anti-mouse secondary antibody (Dako REAL ${ }^{\mathrm{TM}}$; K5005, Dako) was used ( 30 minutes, $23^{\circ} \mathrm{C}$ ) to confirm the level of protein expression after thermal ablation (animal group 1) in comparison to the untreated control group (group 2). Sections were counterstained with hematoxylin.

\section{Analysis of histological staining}

The extent of protein expression was analyzed semiquantitatively. In short, three independent observers evaluated at least three blinded slices of three to six animals per investigated protein and treatment group (BCL2:18 slices, HSP70: 9-15 slices, FGF-R1: 9-18 slices). A categorization was performed according to the specific stained area within the viable tumor region of each slide: 1) completely unstained slides $(0 \%), 2)$ less than half of the viable tumor area stained
$(<50 \%)$, and 3$)$ more than half of the viable tumor area stained $(>50 \%)$. Consensus decisions were performed, if slices were categorized differently. For each protein, the number of slides that were categorized equally was normalized to the total number of slides for each protein staining to receive relative values. Statistical testing was performed using SPSS (Version 21, IBM Corp., USA).

\section{Results \\ Inhomogeneous MNP related heat deposition}

The MNP distribution and successful deposition of the magnetic material after intratumoral application was verified with X-ray images, showing an inhomogeneous distribution of MNP at the injection site before AMF treatment. Distinct temperature increases were obtained in tumors of treated animals (group 1). Temperature curves revealed the highest temperatures (approximately $65^{\circ} \mathrm{C}$ ) in the central tumor region, thus exhibiting the highest iron concentration. In contrast, tumor edges showed lower temperatures confirming the localized heating of the MNP via the AMF. Body temperature was only slightly increased $\left(<39^{\circ} \mathrm{C}\right)$. The highest thermoablative temperatures were reached within 2 minutes after the onset of the AMF, indicating that a sufficient amount of magnetic material was applied to the tumor. Additionally, no delocalization of MNP before and after heat treatment was observed (data not shown).

\section{BCL2, HSP70, FGF-RI protein expression of tumor slices}

In general, histological analyses showed that the BT474 cell line is a not completely de-differentiated adenocarcinoma cell line originating from mammary glands (mucous depositions visible in tumor areas). In the tumors of the treatment group (group 1), clear nanoparticle depositions were observed. Apart from the inhomogeneous MNP distribution, the structure and compactness of the tumor strongly influenced nanoparticle distribution after intratumoral application. In particular, nanoparticles were not completely located in the tumor center (or at the site of injection) since the relatively high intratumoral pressure led to an infiltration of nanoparticles to the surrounding tumor tissue.

Generally, clear morphological differences concerning apoptotic and necrotic areas were obvious when comparing the control and treatment groups. While in the control group almost no apoptotic and necrotic areas were found, these areas were clearly visible in close proximity to MNP depositions in the treatment group. 
Immunohistochemical staining of all tumor slices showed a clear blue staining of nuclei while the protein expression was stained in red (Figure 2). Isotype controls and controls without primary antibody as well as the presence of unstained blood vessels indicated the specificity of the used antibodies (data not shown).

In connection with the oncogene BCL2, a clear downregulation 2 hours after inducing thermoablative temperatures was evident in the sample when comparing the control (group 2, n=6) and treatment (group 1, n=6) groups (Figure 2, BCL2). In both cases, BCL2 was located within the cytoplasm. While in the control group (group 2) all of the investigated slides (six of the six slides) exhibited a stained area of $>50 \%$, in the treatment group (group 1) only $50 \%$ (three of the six slides) of the investigated slides exhibited a stained area of more than $50 \%$. At the same time, 33\% (two of the six slides) of the investigated slides of the treatment group exhibited a stained area of less than 50\%, and 17\% (one of the six slides) of the investigated slides remained unstained without any evidence of BCL2 expression.

When looking at HSP70 expression, an unchanged protein-level at 2 hours after thermoablation in comparison to untreated control animals was observed (Figure 2,
HSP70). Contrary to BCL2, which was expressed within the cytoplasm, HSP70 was additionally, at least partly, present in close proximity to the nucleus. In all investigated slides of the treatment (group 1; five of the five slides) and the control (group 2; three of the three slides) groups, a stained area of more than $50 \%$ was found.

FGF-R1 was mainly found to be expressed within the cytoplasm. It was downregulated in the treatment group (group $1 ; n=6$ ) in comparison to the control group (group 2; $\mathrm{n}=3$ ) at 2 hours after magnetic thermoablation (Figure 2, FGF-R1). In the control group (group 2), 67\% (two of the three slides) of the investigated slides showed a stained area of more than $50 \%$ while $33 \%$ (one of the three slides) showed a stained area of less than $50 \%$. On the contrary, the treatment group (group 1) showed a clear downregulation with no slides exhibiting a stained area of more than $50 \%$. Concurrently, $83 \%$ (five of the six slides) of the investigated slides showed a stained area of less than $50 \%$ while $17 \%$ (one of the six slides) of the investigated slides showed no stained areas, and therefore, no FGF-R1 expression.

Although for BCL2 and FGF-R1, clear differences between the treatment and control groups were visible, these differences were not significant (BCL2: $\chi^{2}=0.135$; FGF-R1:
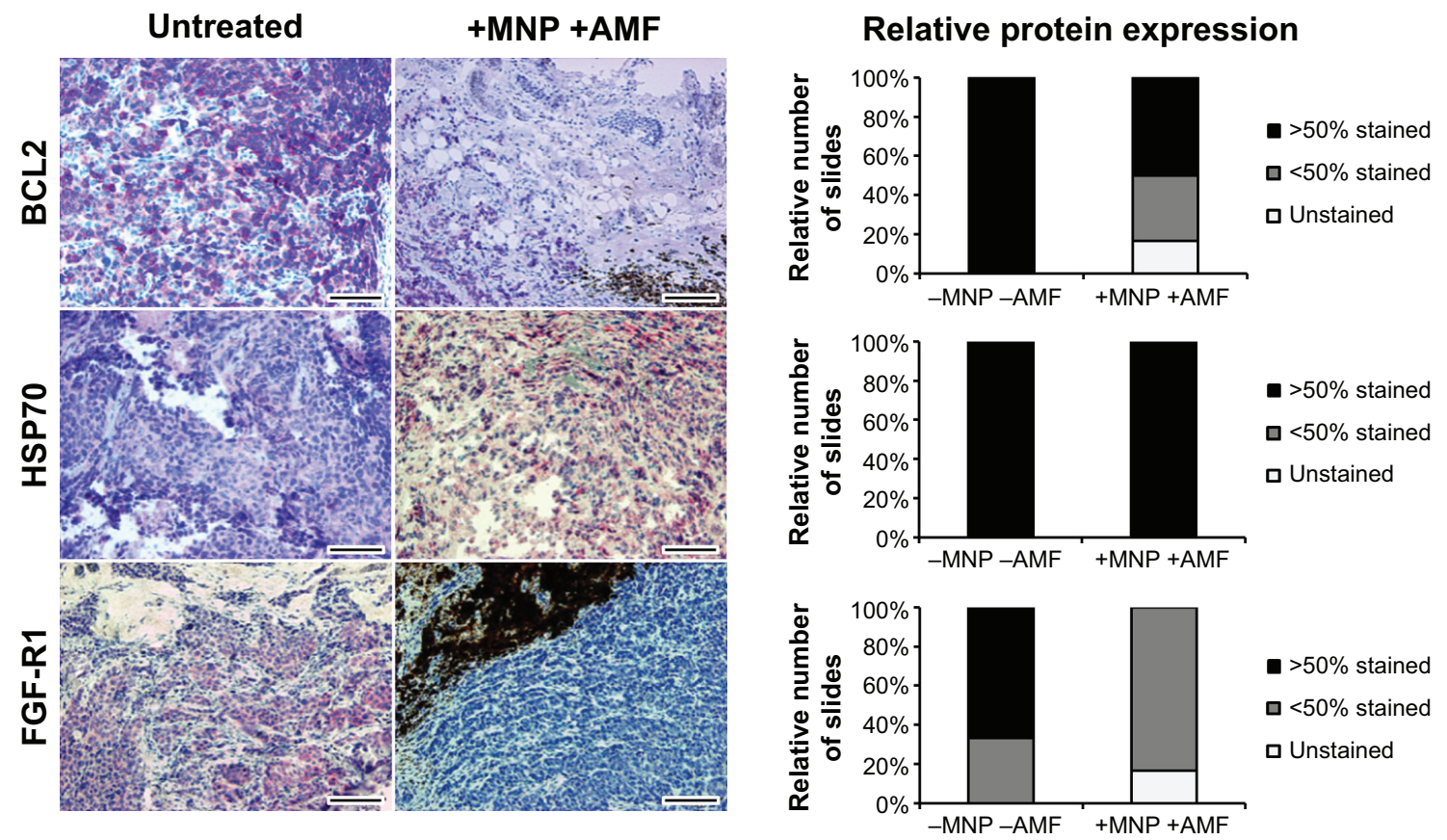

Figure 2 Effect of magnetic thermoablation on the BCL2, HSP70, and FGF-RI protein expression pattern in BT474 tumors.

Notes: Representative pictures after IHC staining of BCL2, HSP70, and FGF-RI were chosen. Blue: nuclei, red: protein-specific antibody, scale bar: I00 $\mu$ m. Relative semiquantitative expression of investigated proteins is depicted in diagrams. In diagrams, bars represent the relative number of slides with a specific protein expression normalized to the total number of all slides in the specific treatment group. Bar colors represent the amount of specifically stained area within the viable tumor region: unstained/negative (light gray), less than $50 \%$ of vital area stained (dark grey), more than $50 \%$ of vital area stained (black). Whereas a downregulation of BCL2 and FGF-RI can be assumed, HSP70 expression remained unchanged.

Abbreviations: BCL2, B-cell lymphoma 2; HSP70, heat shock protein; FGF-RI, fibroblast growth factor receptor I; IHC, immunohistochemistry; MNP, magnetic nanoparticles; AMF, alternating magnetic field. 
$\chi^{2}=0.072$ ) due to the small number of samples in each group. No differences in HSP70 protein expressions of treatment and the control groups were found.

\section{Discussion}

Our data showed that the intratumoral application of the magnetic material led to an inhomogeneous MNP distribution in the tumor region, consequently resulting in an inhomogeneous heat deposition. Furthermore, no delocalization of MNP due to thermoablative treatment could be observed by comparing the X-ray images obtained before and after AMF, and is in accordance with the literature. ${ }^{19}$ Although several publications reported that especially smaller MNP (approximately between $20 \mathrm{~nm}$ and $100 \mathrm{~nm}$ ) were preferentially taken up by tumor cells (eg, by endocytosis), the possibility of the used MNP to be taken up by BT474 tumor cells or, at least, be bound to their membrane was verified in previous experiments. ${ }^{20-22}$

Two hours after the application of thermoablative temperatures in the tumor region, a downregulation of BCL2 and FGF-R1 was found whereas HSP70 remained unchanged. Additionally, more apoptotic and necrotic areas were visible in close proximity to regions with high nanoparticle concentration in the treatment group (group 1) compared to the control group (group 2), indicating the eradication of tumor cells by using heat as a physical stressor.

The protein regulation between the different treatment groups was found not to be significant. Nevertheless, these results provide an insight into protein regulation after short magnetic thermoablative heating.

As shown in the results, histological staining revealed a downregulation of the oncogenic and anti-apoptotic BCL2 protein at 2 hours after inducing thermoablative temperatures (approximately $65^{\circ} \mathrm{C}$ ) in the tumor region by magnetic heating. Generally, a huge variation concerning the heat treatment and BCL2 expression is found in the literature by the utilization of hyperthermic temperatures. A study using chronic myeloid leukemia tumors (K562/A02) in mice in combination with magnetic hyperthermia $\left(40\right.$ minutes, $43^{\circ} \mathrm{C}$ ) reported comparable results in relation to the breast cancer model we used in this study. ${ }^{23}$ Moreover, the use of an exogenous heat source as a more indirect way of heat application by water bath hyperthermia $\left(60\right.$ minutes, $43^{\circ} \mathrm{C}$ ) showed only a slight decrease of BCL2 4 hours after treatment in vivo. ${ }^{18}$ In vitro BCL2 protein is known to be slightly downregulated in tumor cells immediately after heat stress $\left(180\right.$ minutes, $\left.42.5^{\circ} \mathrm{C}\right) .15,16$ Contrarily, the treatment of human colorectal tumor (RKO.C) and isogenic RC10.1 cells to lower temperatures such as
1 hour at $42^{\circ} \mathrm{C}$ (water bath hyperthermia) did not reveal any changes in BCL2 expression. ${ }^{17}$ Presumably, faster and more direct heat generation in tumor tissues (magnetic heating vs water bath hyperthermia) as well as a distinct threshold of temperature dosage is required for a reduction of BCL2 expression, which is readily provided by the utilization of thermoablative stimuli.

HSPs are known to be located at the cell membrane and/or cytoplasm from where they perform their diverse chaperoning functions such as the coordination of protein folding and protection of intracellular molecule functionality. ${ }^{24-27}$ Interestingly, we found HSP70 not exclusively expressed in the cytoplasm but also located in close proximity to the nucleus after induction of thermoablative stimuli. This effect is similar to those observed after hyperthermic conditions: an accumulation of HSP72, an inducible member of the HSP70 family, occurs not only in the cytoplasm but also in the nuclei of mammalian cells directly after exposure to a non-lethal heat shock $\left(240\right.$ minutes, $42^{\circ} \mathrm{C}$ respectively 10 minutes, $45^{\circ} \mathrm{C}$ ) in vitro, supposing an enhanced HSP transcription to evade cellular damage. ${ }^{28,29}$

In the present study, high levels of HSP70 were found in tumors of the control group as well as in the tumors of the treatment group 2 hours after inducing magnetic thermoablation. These observed high HSP70 levels, even in untreated animals of the control group, are in accordance with Stangl et al reporting of a broad variety of human tumors, including breast cancer, exhibiting elevated HSP70 levels that were not present in the related normal tissues. ${ }^{26,27}$ In our study, we could confirm these findings for BT474 breast cancer cell line by IHC stainings. Moreover, the presence of HSP70 per se in the investigated animal groups may also be explained by alterations in the intracellular milieu and/or by stress, ie, by physical exercise, anesthesia, or even the sacrifice $\left(\mathrm{CO}_{2}\right)$ of the animal, resulting in an accumulation of HSPs exemplarily through an increased calcium level, glucose ingestion, $\mathrm{pH}$ alterations, and hypoxia. ${ }^{29-32}$ In the literature, HSP70 expression was shown to peak after an incubation time of approximately 12 hours following 1 hour of heat shock $\left(42.5^{\circ} \mathrm{C}\right)$, indicating a steady expression of HSP70 over a longer time span after heat shock induction on protein level. ${ }^{25}$ Due to this fact, even higher HSP70 levels might be conceivable with ongoing time after magnetic thermoablation. Moreover, it is known that HSP70 can be induced by de novo synthesis of mRNA 2 hours after the induction of heat shock ( 50 minutes, $\left.41.5^{\circ} \mathrm{C}\right) .{ }^{33}$ On the other hand, HSP synthesis is inhibited at temperatures above $45^{\circ} \mathrm{C}$ in dependence of the thermal dose and varies between different cell types. ${ }^{8}$ In the performed 
study, no degradation of HSP70 was found at 2 hours after heat shock. Therefore, longer observation times post therapy may be required for a downregulation or degradation of already elevated HSP70 protein levels in BT474 breast tumors for the given temperature dosages.

We found a downregulation of FGF-R1 at 2 hours after the thermoablative treatment in comparison to untreated controls. In addition to their role in wound healing and angiogenesis, FGF-receptors play an important role in tumorigenesis, metastasis as well as proliferation, migration, differentiation, and invasiveness of tumor cells. ${ }^{34-36}$

Despite its involvement in many regulatory cellular pathways, FGF-R1 is also known to be involved in tumor growth and cellular differentiation. Due to the fact that FGF-R1 is an important part of tumor networks, we were interested in its regulation after inducing short magnetic heating localized to the tumor region. Until now, FGF-R1 has been investigated very rarely in relation with heating-based tumor treatments. Therefore, our data provide a first indication on the molecular level as well as the therapy efficiency of the thermoablative treatment in likely reducing the tumorigenic behavior of human breast cancer BT474 cells in the long term. The fact that magnetic thermoablation is very effective in terms of inducing apoptosis/necrosis and reducing tumor volumes has been shown previously. ${ }^{19}$

Taken together, our results show for the first time the impact of magnetic thermoablative stimuli ( $<2$ minutes) to temperatures up to approximately $65^{\circ} \mathrm{C}$ on the molecular expression pattern of selected proteins in the tumor region 2 hours after heat shock. As previous results have shown, a threshold for thermoablative temperatures for the elimination of tumor cells was found to be $55^{\circ} \mathrm{C}-60^{\circ} \mathrm{C}$ as cell survival was strongly impaired when more than $50 \%$ of total DNA was irreversibly damaged. ${ }^{9}$ In this study, the reduced BCL2 as well as the reduced FGF-R1 protein expression in the treatment group prospectively indicate a reduction of tumorigenicity by negatively influencing anti-apoptotic signaling as well as angiogenesis, metastasis, proliferation, and invasiveness. Further studies using longer post-observation times should corroborate these findings.

\section{Conclusion}

In summary, our data have shown that magnetic heating is capable of inducing effective temperature increases in tumor tissues. Additionally, we found no relocalization of MNP while thermal treatment, offering the possibility for a repeated and localized anti-tumor therapy. The applied thermoablative temperatures are highly likely capable of inducing distinct modifications on the expression patterns of proteins with key roles in cancer development and heat stress response, as it could be seen by comparing the histological staining of treatment and control groups. Therefore, localized magnetic heating offers the possibility of efficiently eradicating tumor cells on molecular as well as physical levels and therefore is capable of reducing the patient's tumor burden.

\section{Acknowledgments}

M Stapf is the main author of this manuscript. The present investigation was supported in part by the "Deutsche Forschungsgemeinschaft" (HI-689/7-2). We acknowledge valuable technical assistance provided by $\mathrm{S}$ Burgold, J Göring, B Grobis, Y Ozegowski, and B Ziegenhardt. We acknowledge Dr B Romeike for assisting in examining the histological slices and Dr L Leistritz for his advice in statistical calculations. We thank S Nietzsche (Center of Electron Microscopy, University Hospital Jena, Germany) for kindly providing the HRTEM micrographs of $200 \mathrm{~nm}$ fluidMAG-D MNP (Figure S1). This work is dedicated to WA Kaiser who passed away in 2013.

\section{Disclosure}

The authors report no conflicts of interest in this work.

\section{References}

1. Stauffer PR. Evolving technology for thermal therapy of cancer. Int $J$ Hyperthermia. 2005;21(8):731-744.

2. Diederich CJ. Thermal ablation and high-temperature thermal therapy: overview of technology and clinical implementation. Int J Hyperthermia. 2005;21(8):745-753.

3. Hilger I, Andra W, Hergt R, Hiergeist R, Schubert H, Kaiser WA. Electromagnetic heating of breast tumors in interventional radiology: in vitro and in vivo studies in human cadavers and mice. Radiology. 2001;218(2):570-575.

4. Jordan A, Wust P, Scholz R, et al. Cellular uptake of magnetic fluid particles and their effects on human adenocarcinoma cells exposed to AC magnetic fields in vitro. Int J Hyperthermia. 1996;12(6):705-722.

5. Hilger I, Hergt R, Kaiser WA. Towards breast cancer treatment by magnetic heating. J Magn Magn Mater. 2005;293(1):314-319.

6. Zhang HG, Mehta K, Cohen P, Guha C. Hyperthermia on immune regulation: a temperature's story. Cancer Lett. 2008;271(2):191-204.

7. Franke K, Kettering M, Lange K, Kaiser WA, Hilger I. The exposure of cancer cells to hyperthermia, iron oxide nanoparticles, and mitomycin $\mathrm{C}$ influences membrane multidrug resistance protein expression levels. Int J Nanomedicine. 2013;8:351-363.

8. Hildebrandt B, Wust P, Ahlers $\mathrm{O}$, et al. The cellular and molecular basis of hyperthermia. Crit Rev Oncol Hematol. 2002;43(1):33-56.

9. Hilger I, Rapp A, Greulich KO, Kaiser WA. Assessment of DNA damage in target tumor cells after thermoablation in mice. Radiology. 2005;237(2):500-506

10. Ritossa F. New puffing pattern induced by temperature shock and DNP in Drosophila. Experientia. 1962;18(12):571.

11. Heike M. Stimulation of tumor reactive T-cells by tumor-derived stress proteins - implications for vaccine development. Eur J Cancer. 1999;35:S9-S9. 
12. Cui NZ, Xu YP, Cao ZH, Xu FX, Zhang P, Jin LJ. Effects of heat stress on the level of heat shock protein 70 on the surface of hepatocellular carcinoma Hep G2 cells: implications for the treatment of tumors. Tumour Biol. 2013;34(2):743-748.

13. Chong KY, Lai CC, Su CY. Inducible and constitutive HSP70s confer synergistic resistance against metabolic challenges. Biochem Biophys Res Commun. 2013;430(2):774-779.

14. Fujimoto J, Ichigo S, Hori M, Hirose R, Sakaguchi H, Tamaya T. Expression of basic fibroblast growth factor and its mRNA in advanced uterine cervical cancers. Cancer Lett. 1997;111(1-2):21-26.

15. Salah-Eldin AE, Inoue S, Tsukamoto SE, Aoi H, Tsuda M. An association of Bcl-2 phosphorylation and Bax localization with their functions after hyperthermia and paclitaxel treatment. Int $J$ Cancer. 2003;103(1):53-60.

16. Nishita M, Inoue S, Tsuda M, Tateda C, Miyashita T. Nuclear translocation and increased expression of Bax and disturbance in cell cycle progression without prominent apoptosis induced by hyperthermia. Exp Cell Res. 1998;244(1):357-366.

17. Ohtsubo T, Park HJ, Lyons JC, Ohnishi T, Song CW. Effect of acidic environment and p53 on apoptosis induction by hyperthermia. Int $J$ Hyperthermia. 2000;16(6):481-491.

18. Liang H, Zhan HJ, Wang BG, Pan Y, Hao XS. Change in expression of apoptosis genes after hyperthermia, chemotherapy and radiotherapy in human colon cancer transplanted into nude mice. World J Gastroenterol. 2007;13(32):4365-4371.

19. Kettering M, Richter H, Wiekhorst F, et al. Minimal-invasive magnetic heating of tumors does not alter intra-tumoral nanoparticle accumulation, allowing for repeated therapy sessions: an in vivo study in mice. Nanotechnology. 2011;22(50):505102-505102.

20. Iversen T-G, Skotland T, Sandvig K. Endocytosis and intracellular transport of nanoparticles: present knowledge and need for future studies. Nano Today. 2011;6(2):176-185.

21. Kettering M, Winter J, Zeisberger M, et al. Magnetic nanoparticles as bimodal tools in magnetically induced labeling and magnetic heating of tumor cells: an in vitro study. Nanotechnology. 2007; 18(17):175101-175101.

22. Karimi Z, Karimi L, Shokrollahi H. Nano-magnetic particles used in biomedicine: core and coating materials. Mater Sci Eng C Mater Biol Appl. 2013;33(5):2465-2475.

23. Chen B, Ren Y. Multifunctional magnetic Fe3O4 nanoparticles combined with chemotherapy and hyperthermia to overcome multidrug resistance. Int J Nanomedicine. 2012;7:2261-2269.

24. Multhoff G, Botzler C, Wiesnet M, et al. A stress-inducible 72-kDa heat-shock protein (Hsp72) is expressed on the surface of human tumorcells, but not on normal-cells. Int J Cancer. 1995;61(2):272-279.
25. Schneider EM, Niess AM. Inducible HSP70 expression analysis after heat and physical exercise. Ann N Y Acad Sci. 2002;1:5-9.

26. Stangl S, Gehrmann M, Dressel R, et al. In vivo imaging of CT26 mouse tumors by using cmHsp70.1 monoclonal antibody. J Cell Mol Med. 2011;15(4):874-887.

27. Stangl S, Gehrmann M, Riegger J, et al. Targeting membrane heat-shock protein 70 (Hsp70) on tumors by cmHsp70.1 antibody. Proc Natl Acad Sci U S A. 2011;108(2):733-738.

28. Welch WJ, Feramisco JR. Nuclear and nucleolar localization of the 72,000-dalton heat shock protein in heat-shocked mammalian cells. J Biol Chem. 1984;259(7):4501-4513.

29. Kiang JG, Carr FE, Burns MR, McClain DE. HSP-72 synthesis is promoted by increase in [Ca2+]i or activation of $\mathrm{G}$ proteins but not pHi or cAMP. Am J Physiol. 1994;267(1 pt 1):C104-C114.

30. Febbraio MA, Mesa JL, Chung J, et al. Glucose ingestion attenuates the exercise-induced increase in circulating heat shock protein 72 and heat shock protein 60 in humans. Cell Stress Chaperones. 2004;9(4):390-396.

31. Gapen CJ, Moseley PL. Acidosis alters the hyperthermic cytotoxicity and the cellular stress response. Fish Physiol Biochem. 1995; 20(4):321-325.

32. Benjamin IJ, Kröger B, Williams RS. Activation of the heat shock transcription factor by hypoxia in mammalian cells. Proc Natl Acad Sci U S A. 1990;87(16):6263-6267.

33. Schiaffonati L, Tacchini L, Pappalardo C. Heat shock response in the liver: expression and regulation of the hsp70 gene family and early response genes after in vivo hyperthermia. Hepatology. 1994;20(4 pt 1): 975-983.

34. Cao R, Bråkenhielm E, Pawliuk R. Angiogenic synergism, vascular stability and improvement of hind-limb ischemia by a combination of PDGF-BB and FGF-2. Nat Med. 2003;9(5):604-613.

35. Boilly B, Vercoutter-Edouart AS, Hondermarck H, Nurcombe V, Le Bourhis X. FGF signals for cell proliferation and migration through different pathways. Cytokine Growth Factor Rev. 2000;11(4):295-302.

36. Taylor WR, Greenberg AH, Turley EA, Wright JA. Cell motility, invasion, and malignancy induced by overexpression of K-FGF or bFGF. Exp Cell Res. 1993;204:295-301.

37. Ludwig R, Stapf M, Dutz S, Muller R, Teichgraber U, Hilger I. Structural properties of magnetic nanoparticles determine their heating behavior - an estimation of the in vivo heating potential. Nanoscale Res Lett. 2014;9(1):602. 


\section{Supplementary material}

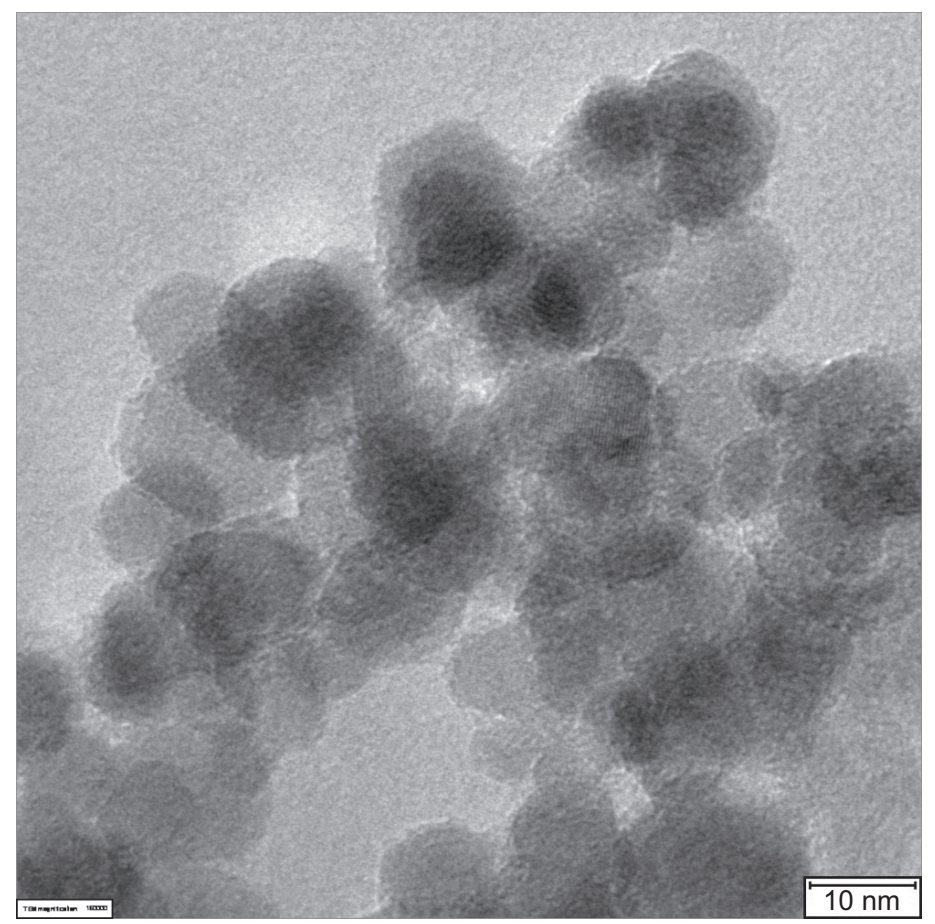

Figure SI High-resolution transmission electron microscopy (HRTEM) micrograph of $200 \mathrm{~nm}$ fluidMAG-D magnetic nanoparticles (MNP).

Notes: HRTEM micrograph reveals smaller core particles of approximately $10-12 \mathrm{~nm}$ in size clustered to a particle core size of approximately $70 \mathrm{~nm}$ in total. The HRTEM micrograph was prepared as described elsewhere. ${ }^{37}$

\section{Publish your work in this journal}

The International Journal of Nanomedicine is an international, peerreviewed journal focusing on the application of nanotechnology in diagnostics, therapeutics, and drug delivery systems throughou the biomedical field. This journal is indexed on PubMed Central,

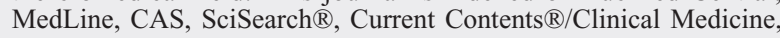

Journal Citation Reports/Science Edition, EMBase, Scopus and the Elsevier Bibliographic databases. The manuscript management system is completely online and includes a very quick and fair peer-review system, which is all easy to use. Visit http://www.dovepress.com/ testimonials.php to read real quotes from published authors.

\footnotetext{
Submit your manuscript here: http://www.dovepress.com/international-journal-of-nanomedicine-journal
} 